20 - 22 August 2021

Dublin, Ireland

\title{
Design of a Drinking Water Treatment practice as a virtual lab to support higher education teaching in COVID-19 outbreak
}

\author{
J. I. Méndez-Ruiz, P. E. Valverde.
}

ESPOL Polytechnic University, Escuela Superior Politécnica del Litoral, ESPOL, Faculty of Engineering in Earth Sciences, Campus Gustavo Galindo Km. 30.5 Via Perimetral, P.O Box 09-01-5863, Guayaquil-Ecuador

\begin{abstract}
The COVID-19 outbreak has been a challenge for the education system worldwide. The faceto-face activities had to turn to virtual environments despite the fact educational institutions were prepared or not. One of the challenges of this 'sudden' change was the limitation to attend to hands-on laboratories which are essential to develop the experimental skills of the students. In order to response rapidly to this need, most of the hands-on practices of the Drinking Water Treatment subject were virtualized as part of a project in the Faculty of Engineering in Earth Sciences of Escuela Superior Politécnica del Litoral. This study shows the design process of the Jar Test experiment using a low-cost online platform to replicate both the practice and the lab facility. This online platform comprises of block-based programming language that helped to simulate physical-chemical phenomena that occur during the treatability tests in the face-to-face lab. The usefulness of this resource as a support teaching material is discussed in order to deploy improvement actions.
\end{abstract}

Keywords: CoSpaces; experimental design; experimental procedures; e-learning; programming. 